\title{
The Security Implications of the Beggary Phenomenon: Treatment and Prevention Methods
}

\author{
Bashar Samir Deli \\ Directorate of Sunni Endowment in Anbar, Iraq \\ edreeslake20@gmail.com
}

\begin{abstract}
KEYWORDS: $\quad$ Security, Phenomenon, Beggary, Prevention, Treatment.
\end{abstract}
Crossref doi https://doi.org/10.51345/.v32i4.427.g246

\begin{abstract}
:
Begging is an issue that affects civilizations of various cultures and their children's behavior, which can lead to criminality and society security breaches. There are societal and economic explanations behind this phenomenon, and the techniques for dealing with poverty are discussed, including a prophetic remedy when the Prophet is in need (peace be upon him) commanded the companion to do something better for him than asking people, so the Messenger of God said to him: "This is better for you than for the question to come as a black mark on your face on the Day of Resurrection, for the question is only suitable for three: the one who is extremely poor, or the one who is deeply in debt, or the one who has painful blood." He warned against beggary and explained the punishment for it in the hereafter. This was a practical and guiding treatment. Also, one of the things that deals with this bad behavior is teamwork, which in turn creates opportunities to engage young people in work that deviates them and attracts them to the right path to be an effective element in building a good society, then we show in the conclusion, the results, recommendations and suggestions through which we can eliminate the phenomenon of beggary.
\end{abstract}




\title{
الآثار الأمنية لظاهرة التسول وسبل العلاج والوقاية
}

\author{
م.م. بشار سمير دلي \\ مديرية الوقف السني في الأنبار، العراق \\ edreeslake20@gmail.com
}

الكلمات المفتاحية | الأمن، ظاهرة، التسول، الوقاية، العلاج.

Crossref doi https://doi.org/10.51345/.v32i4.427.g246

\section{ملخص البحث:}

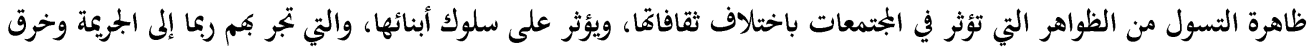

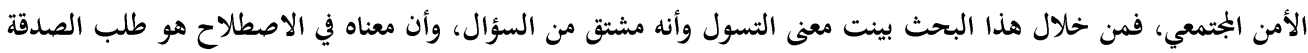

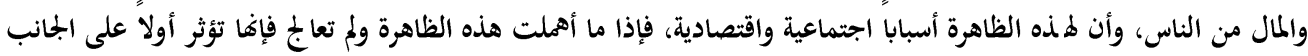

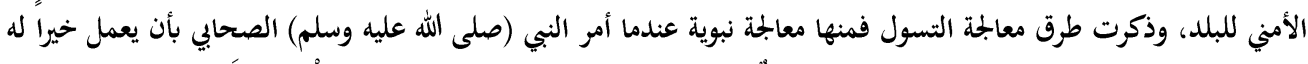

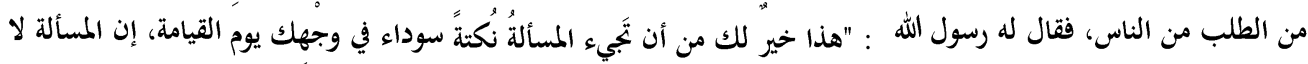

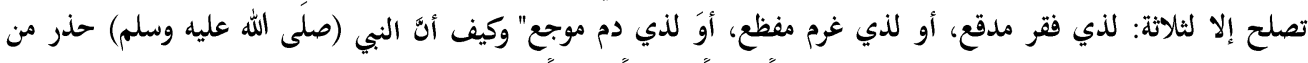

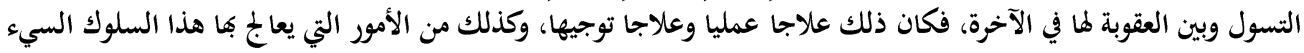

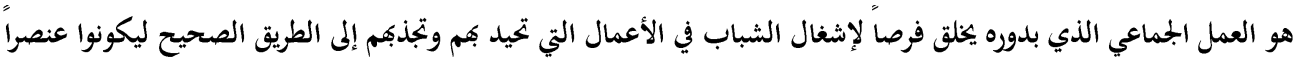

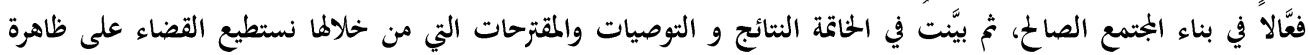
التسول.

المقدمة:

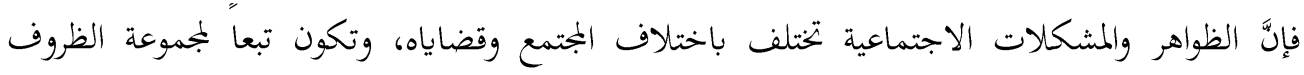

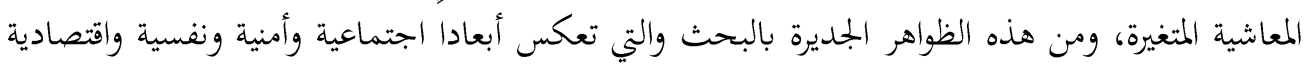
ملفتة للنظر لبروزها في المجتمع وظهورها خارجا عن المألوف الاجتماعي ألا وهي ظاهرة التسول والتي تزداد في الجمتمعات التي تعاني أزمة اقتصادية، ويرتفع فيها معدلات البطالة، وتتخذ هذه لئه الظاهرة أشكالاً باختلاف ثقافات وعادات الجمتمع. ولما لهذه الظاهرة من تأثير سلبي على الأمن المجتمعي أولاً، وعلى سلوكيات الشباب وحتى من هم دون سن فئس

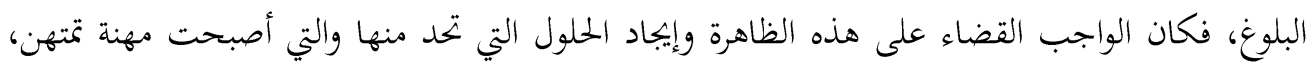


فمن خلال هذه الدراسة التي تناولت فيها هذه المشكلة وما لها من تأثير سلبي على المجتمع من كل جوانبه،

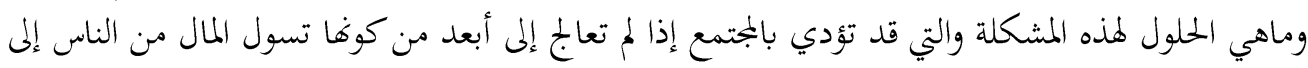
السرقة والجريمة بكل أشكالها. ومن هذا المنطلق جاءت هذه الدراسة لتأخذ ظاهرة "التسول" موضوعاً لها، مراعية كافة الجوانب المحيطة بها، وكذلك بعدها الأمني الذي يعد ضرورة حتمية للفرد، والمجتمع على حد سواء، وبشكل لا يمكن فيه الفصل

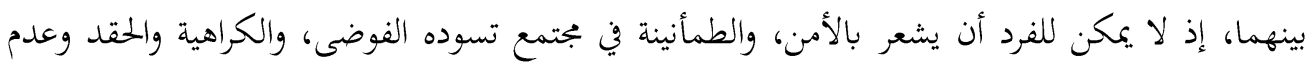
التوازن، ومن هذا المنطلق بدأت الدول الحديثة بالاعتماد على مفهوم جديد لمكافحة ولئحة هذه الظاهرة في بجتمعاتا من خلال الوقاية منها، بتعاون حكومي مشترك، وذلك بمنع توفر مناخ وعوامل وظروف الجريمة

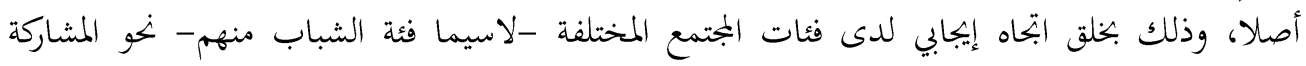
الأمنية من أجل تحويل تلك الاتحاهات إلى سلوك ممارس، فتكمن أهمية هذه الدراسة في محاولة استقصاء هذا الجانب الأمني لظاهرة التسول الذي لم يهظ بالبحث الكافي، كما حظيت به الجوانب الأخرى للظاهرة وما تسفر عنه من نتائج وتوصيات ومقترحات في هذا الشأن.

\section{أولاً: مشكلة الدراسة:}

تكمن في تفاقم ظاهرة التسول في المجتمع وانتشارها، الأمر الذي قد يهدد أمنه واستقراره، حيث تحاول هذه الدراسة معرفة مدى خطورة تلك الظاهرة على الناحية الأمنية فيه، والتي يمكن صياغتها بالتساؤل التالي: ـ ما الأبعاد الأمنية لظاهرة التسول في المجتمع؟.

\section{ثانيا: أهمية الدراسة:}

تكمن أهمية الدراسة لموضوع في تحقيق الفوائد التالية:

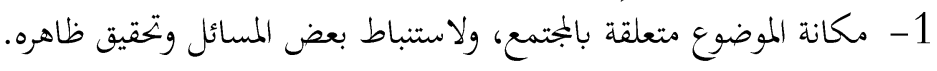

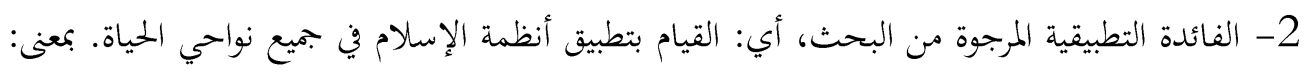

$$
\text { إنزال الكلمات على الواقع. }
$$

3- إنَّ في دراسة هذا الموضوع استجابة لأوامر الله سبحانه وتعالى عندما حثَّ الحفاظ على الأمن الذي يهدد المجتمعات. 4- الفائدة العلمية، وتتمثل في بيان الجوانب التي يتميز بها هذا البحث عن الدراسات السابقة 5- حل المشكلات التي تنتظم البحث، وإيجاد طرق العلاج السليمة والمناسبة لها. 
على الرغم من أن هناك عددا من الدراسات تناولت ظاهرة التسول في العديد من الجوانب إلا أن الجوانب الأمنية لهذه الظاهرة، ما زالت بحاجة لمزيد من الدراسات كي تتضح العلاقة بين انتشار ظاهرة التسول في

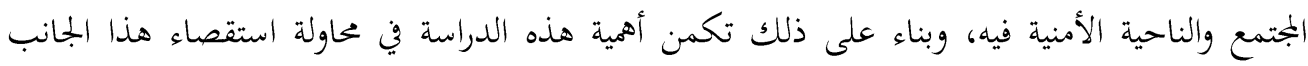
الأمني لظاهرة التسول الذي لم يحظ بالبحث الكافي، كما حظيت به الجموانب الأبهاء الخرى للظاهرة وما تسفر عنه من نتائج وتوصيات ومقترحات في هذا الشأن، الأهمية العلمية، الأهمية العملية.

\section{ثالثا: اختيار الموضوع:}

إن دراسة موضوع الآثار الأمنية لظاهرة التسول وسبل العلاج والوقاية في مجتمعنا العراقي، لهو من دواعي توطيد العلاقة المتبادلة بين المواطن ورجل الأمن وتدعيمهما؛ من أجل تحقيق قدر أكبر من الأمن في الجمتمع،

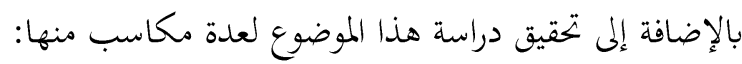
1- الإسهام في نجاح رجال الأمن في تحقيق رسالتهم، وتخفيف جزء كبير من العبء الملقى على عاتقهم.

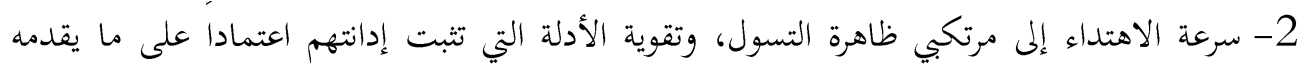
الجمتمع المشاركون من بيانات ومعلومات لرجال الأمن. 3- دعم رجال الأمن بأعداد هائلة من القوى البشرية التي تقدم خدمات ملمعات ملموسة من أئمة المساجد وطلاب العلم الشرعي يساعد دون أن تحمل الدولة بأية أعباء مالية.

\section{رابعا: أهداف الدراسة:}

تتمثل أهداف هذه الدراسة في التالي:

1- معرفة المشكلات الأمنية المترتبة على ظاهرة التسول في المجتمع ومكافحتها فعلياً.

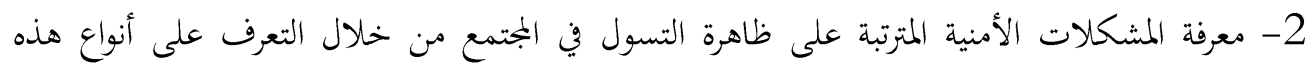
المشكلة وتحديد حجم انتشارها.

3- معرفة الأبعاد المرتبطة بأبعاد الوقاية من ظاهرة التسول، والحد منها مندان من خلال التعرف على معوقات هذه الظاهرة، واتخاذ سبل العلاج والوقاية المقترحة للحد منها. 4- معرفة العلاقة بين دور مؤسسات تدعيم المشاركة الأمنية" الأسرة، والمسجد، ولهدة وسائل الإعلام" وبين

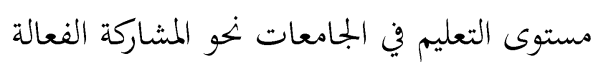




\section{خامسا: تساؤلات الدراسة:}

تطرح هذه الدراسة التساؤلات التالية:

1- ما دور أئمة وخطباء المساجد في محاربة تلك ظاهرة وتوجيه الناس في تدعيم تحقيق الأمن؟

2- ما مستوى قبول الناس للتصدي مثل هذه نحو تعاون مع الأجهزة الأمنية؟ فئج

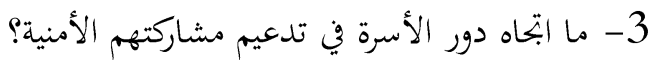

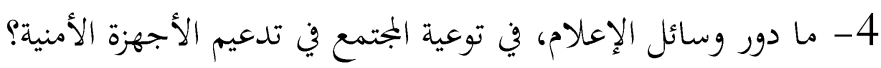

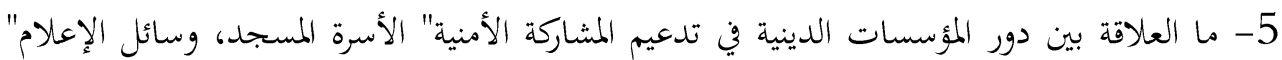
وبين الاجهزة الأمنية ومشاركتها؟

\section{سادسا: حدود الدراسة:}

البحث يقتصر على ظاهرة التسول، وكيفية معالجتها، ودراستها أمنياً.

\section{المبحث الأول: مفهوم التسول}

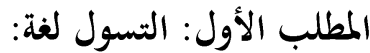

لم يستخدم لفظ التسول في القرآن أو في السنة، وإنما استخدم لفظ المسألة، ولفظ التكفف، أما لفظ التسول فقد ساد في الوقت الحاضر، وحل محل المسألة، وصار اللفظ المعتمد في التشريعات المدنية المحديثة، ويعبر عنه في التشريعات العربية بألفاظ أخرى هي: الاستجداء(1)، والتكفف وحلف (2)، ويطلق عليه بعض الناس لفظ الشحاذة(3)؛ ولذا سنتعرض إلى دراسة ظاهرة التسول في المسائل الآتية.

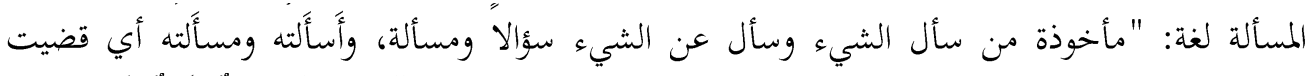

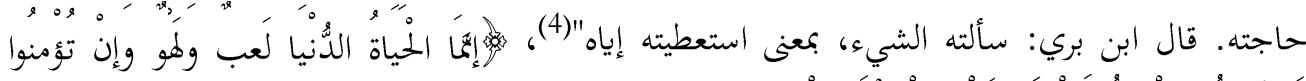

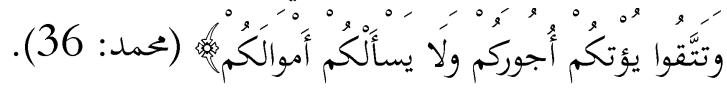

المطلب الثاني: التسول اصطلاحاً

والتسول: هو الاستعطاء وطلب الصدقة من الناس باستخدام وسائل مختلفة لاستدرار العطف والشفقة (5). أما مفهوم التسول في معناه العام: (هو طلب الصدقة من الافراد في الطرق والأماكن العامة أو بمنازهم، وهو بذلك سلوك يقوم على استجداء الآخرين من خلال استخدام وسائل تأثير مختلفة، وهو أيضا سلوك إنساني 
يتسم بالاستمرارية ويختلف عن طلب المساعدة من الآخرين لظروف عارضة أو صعبة يجربها الفرد أو الأسرة،

ويختلف عن العطاء الاختياري الذي يقدمه الفرد للآخرين طوعا في إطار التبرع أو الصدقة أو الزكاة)(6) ظاهرة التسول: التسول يعني الاستجداء أو المساءلة بمعنى أن يقوم المرء بحث الآخرين على أن يتصدقوا عليه لحاجة أو بدون حاجة وله أشكال عدة، منها: ما يأخذ شكل الاستعطاف في الحالات التي يعاني فيها المتسول من عاهة، كقطع اليد أو الرجل، ومنها ما يأخذ شكل البيع والمتاجرة بسلع رخيصة يعرضها المتسول على المارة(7)، من خلال عرضنا لذذه التعاريف يتضح لنا أن التسول هو طلب المساعدة والعون من أفراد المجتمع بشتى الطرق المختلفة بغية الحصول على مساعداتم سواء كانت مالية أو عينية المتمثلة في الملبس والأطعمة وغير ذلك من الأشياء النفعية.

المبحث الثاني: اسباب ظاهرة التسول والآثار الامنية المترتبة على ذلك

\section{المطلب الأول: اسباب ظاهرة التسول: - مأن}

أما ما له علاقة بأسباب هذه الظاهرة، فمنها ما هو: 1- اجتماعي، وهو غياب الرقيب العائلي واختلاط الأطفال بأصدقاء السوء في ظل التوتر والشقاق

والخلاف بين أفراد الأسرة، محا ينعكس سلبا على تنشئة الأطفال(8).

2- ومنها ما هو اقتصادي، وهو أن بعضا من المتسولين ليس لديه الرغبة في العمل أو الكسب، إلا أن البطالة وقلة فرص العمل حالت دون عمله، أو لعدم القدرة على العمل لعاهة به حالت دون ذلك

لذلك يلجأ المرء لامتهان التسول(9). 3- أما ما له علاقة بأثار هذه الظاهرة، فإنه ثمة علاقة وطيدة بين هذه الظاهرة وبين الحراف الأحداث بصفة خاصة، فكلما كان الحدث صغيرا، عندما تسول تكرر لديه الشعور بعدم الرغبة في العمل

$$
\text { والاهتمام بمستقبله (10). }
$$

"لقد كثر ظاهرة التسول فوجد يفاجئون الناس في الطريق، وقد فقدوا كل رعاية والاهتمام من ولاة أمورهم، فلا أسرة تمدهم بالعطف الحنان، ليخرج من الشذاذ الذين يستلون أموال الناس، فإن حال حائل دون أن يستلوا هذا الاستلاب استلبوا الأرواح ليصلوا الى مبتغاهم، ولقد حاول العلماء أن يتعرفوا أسباب ذلك الداء الذي يفتك بالمجتمع العربي، فقال بعض ذوى السلطان أن سببه الطلاق وتعدد الزوجات وإنه إذا قيد الطلاق وقيد تعدد الزوجات زال ذلك السبل من المتسولين، أو خف وضعف أثره"(11) 


\section{المطلب الثاني: العمل التطوعي وعلاقته بظاهرة التسول وما يترتب عليها آثار أمنية:}

لا شكَ أن للعمل التطوعي الأثر الكبير في تحقيق الأمن والاستقرار الاجتماعي، أولاً بأدائه الدور الكامل

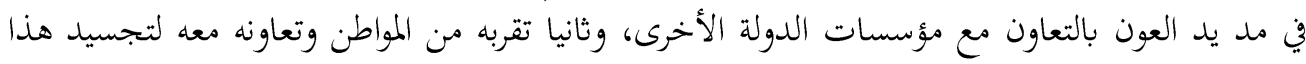
الأمن. (n) والأمن الاجتماعي بمفهومه البسيط يعني سلامة الأفراد والجماعات من الأخطار الداخلية والخارجية التي

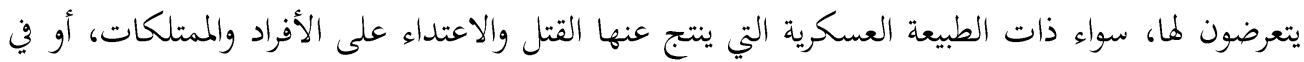

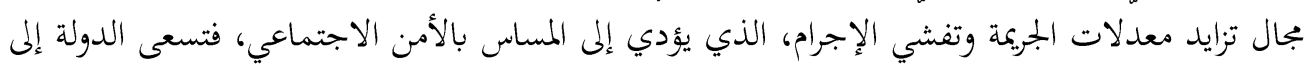

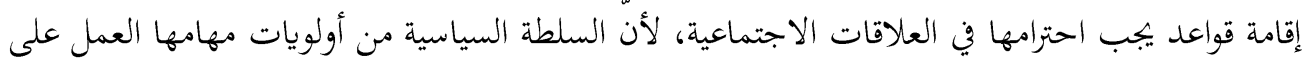

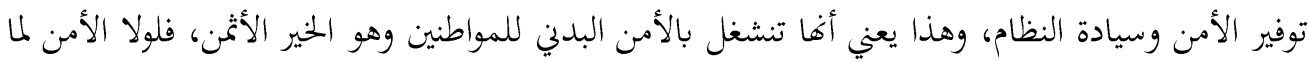

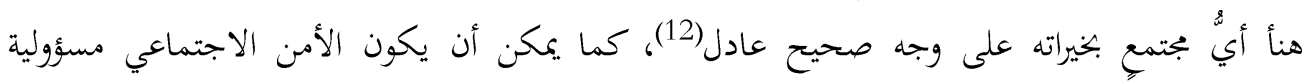
اجتماعية بوصفه ينبع من مسؤولية الفرد بتاه نفسه وأسرته، وبهذا نشأت أعراف العشيرة وتقاليدها، لتصبح

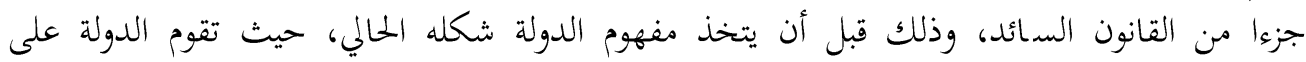

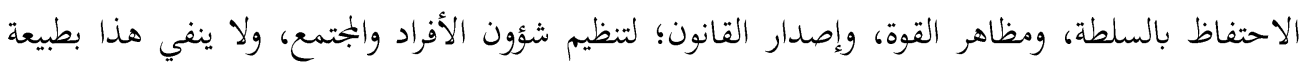

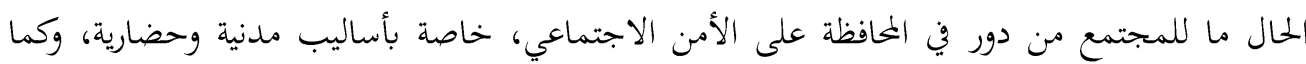
يكون الأمن في الضرورات والحاجات المادية، يكون كذلك في الأمور المعنوية والنفسية والروحية، وكما يكون للفرد فإنه يكون للاجتماع الإنساني العام(13). إنه لمن دواعي الامن النفسي للفرد والمجتمع، على اختلاف طوائفه وطبقاته، أن يعتقد الناس ويقر في قلوبهم

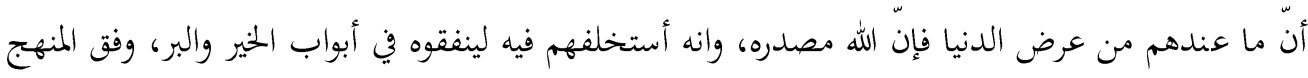

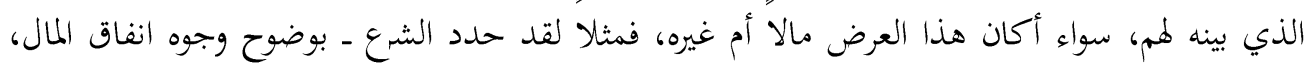

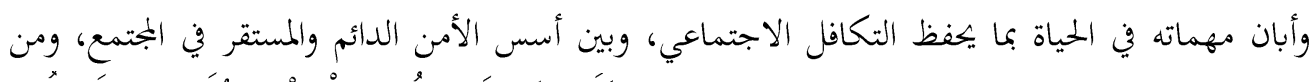

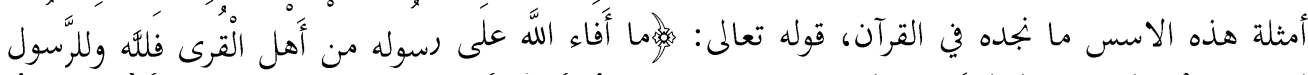

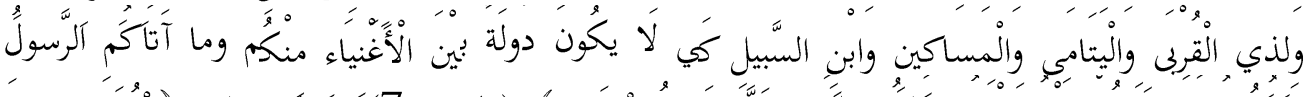

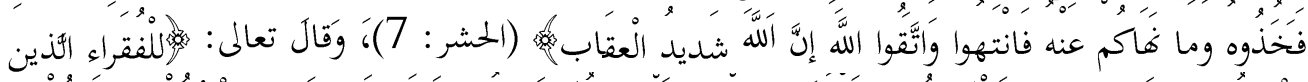

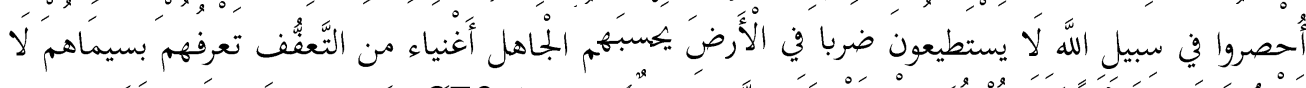

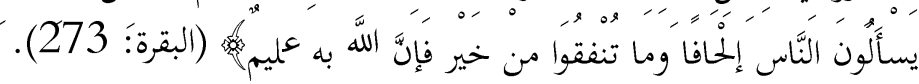


ومن الأحاديث النبوية: روي أنَّهَ أصيب رجل في عهد رسول الله في ثمار ابتاعها فكثر دينه فَقالَ رسولُ الله:

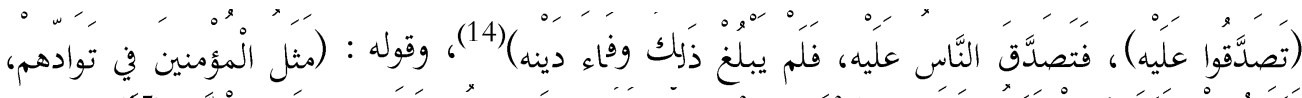

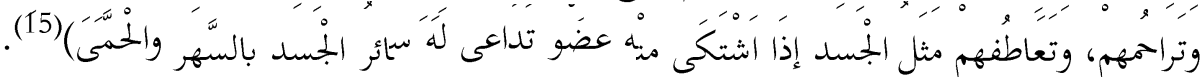

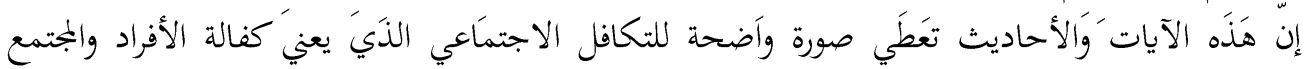
جميعا فيما يتعرضون له من خسائر اقتصادية وبما يتفق مع حاجاتم الشخصية لضمان تحررهم من الفاقة والعوز بسبب العوامل الاقتصادية التي تعوق الحصول على الدخل المناسب، ومن أهمها البطالة(16).

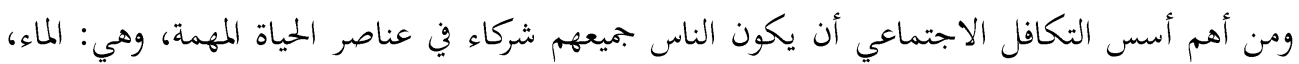
والكلأ، والنار، والتي بينها رسول الله بقوله: (المسلمون شركاء في ثلاث: الماء، والكالا، والنار)(17)، وتحقيق الأمن يعتبر مسؤولية اجتماعية؛ حيث أصبح العمل التطوعي ركيزة أساسية لبناء المسؤولية الاجتماعية بتحاه الأمن؛ لأن العمل التطوعي والخيري يعتبر أحد الروافد الأساسية لأمن المجتمع واستقراره.

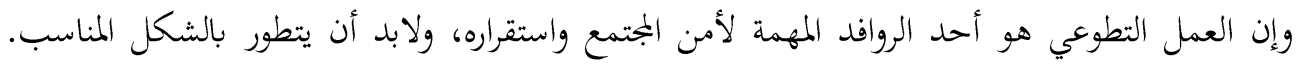

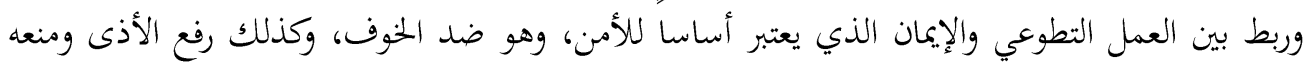

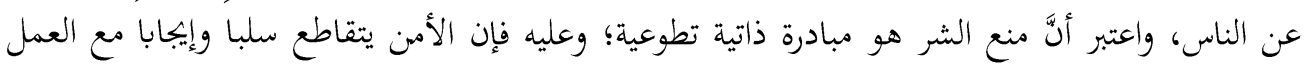
التطوعي. إنَّ الشباب لهم دور كبير في العمل التطوعي الأمني، باعتبار أنَّ تعاون المواطنين مع الجهات الأمنية يشكل

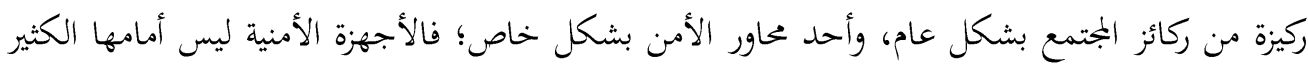

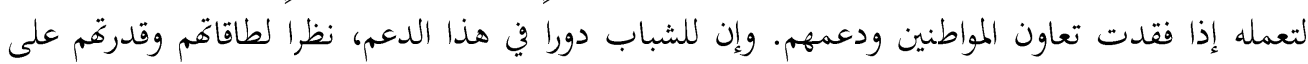
العمل التطوعي وهذا يسهم في حجب طاقات الشباب عن ميادين الانحراف، واستغلال طاقات الشباب في الحفاظ على الأمن واستقراره ومكافحة الجريمة.

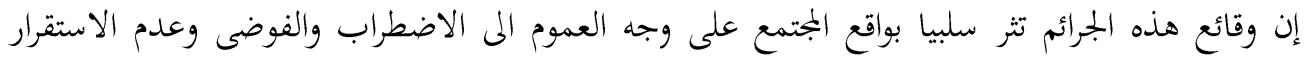

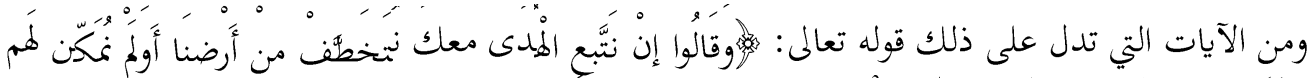

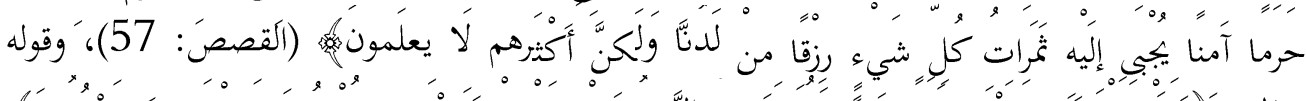

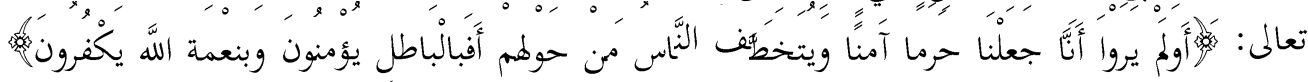

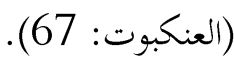


(أو لم يكونوا آمنين في حرمهم لا يغزون فيه فلا يخافون... وكان العرب يغير بعضهم على بعض)(18)، (كانت العرب حول مكة يغزو بعضهم بعضا ويتناهبون، وأهل مكة قارون آمنون فيها لا يغار عليهم مع بعريم

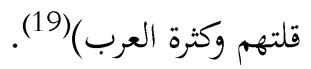
يتبين الأمر أن القصص القرآني فيه أوجه التشابه بين تلك الفترة التي انتهت بها تلك المجتمعات وما تمر به

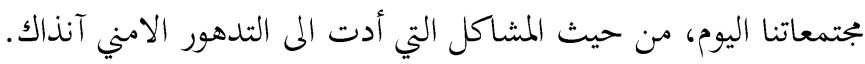
كما أن ظاهرة الإجرام والإجرام المنظم يمكن مكافحتها عن طريق العمل التطوعي والوقاية منها، والمهم هنا هو تضييق الحصار على المجرمين والعابثين بأمن الجمتمع واستقراره في المنطقة العربية والإسلامية، والجمتمع البشري عامة، هو أحد بجالات العمل التطوعي، ويمكن للعمل التطوعي أن يكون له دور في هذا المجال من لهن خلال التوعية بالمخاطر عن طريق وسائل الإعلام، والمساجد، والمؤسسات العلمية والثقافية، وضرورة

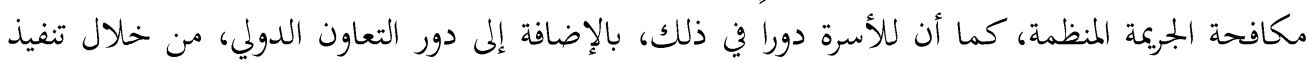
الاتفاقيات الدولية والتوصيات بمكافحة الإجرام والجريمة المنظمة، ولبيان أثر العمل التطوعي في الاصلاح.

الآثار الامنية

في ظل الظروف الاجتماعية والبيئية والإنسانية والاقتصادية المعاصرة، تبرز الحاجة الآن إلى دور العمل التطوعي الفاعل في تحقيق الأمن الاجتماعي والاقتصادي، وهذا ما جعل الجهات الرسمية في مختلف الدول تسعى لتفعيل دور العمل التطوعي، وذلك من خلال حث الناس عليه، وتنظيمه في قنوات شرعية؛ حتى يجقق الغاية منه.

ولاشك أن التوعية بأهمية العمل التطوعي تأتي في مقدمة الأعمال اللازمة والضرورية في هذا المجال؛ لتؤكد جوهرية العلاقة بين العمل التطوعي والأمن، وتبرز الدور الذي يستطيع أن يؤديه العمل التطوعي في ميدان

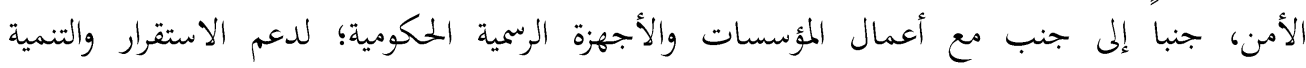
الاجتماعية والاقتصادية، كما تؤكد أهمية العمل التطوعي في الوقاية من الجريمة والانحراف؛ وذلك من خلال

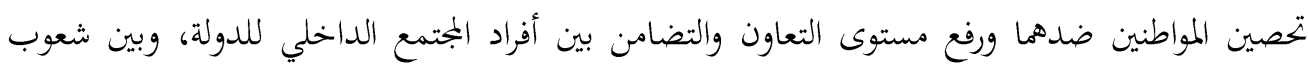
العالم أجمع، لاسيما في ظل عولمة الجريمة. لقد تكلم الإمام محمد أبو زهرة(20): عن حالة المجتمعات الإنسانية قبل الإسلام بعد أن قسم الجمتمعات

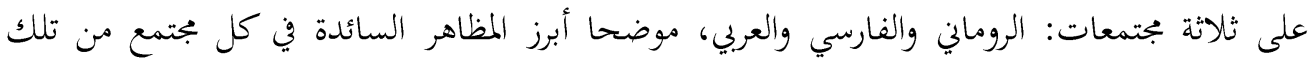

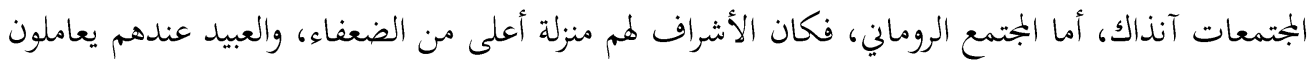

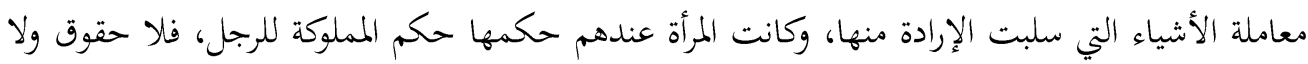


واجبات بين الرجل والمرأة، وكانت الفتن الدينية مستمرة، فالوثنيون اضطهدوا المسيحيين اضطهادا بلغ حد الحرق بالنار (21) أما الجمتمع الفارسي، فقد تفرقت فارس سياسيا، ومعه التفرق الاجتماعي، إذ كان الحكم للأشراف دون

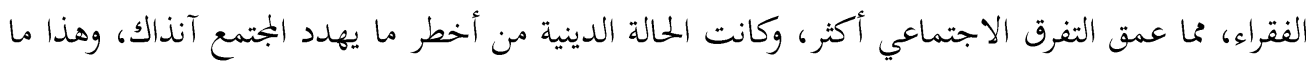
دفع إلى اهيار المجتمع الفارسي نتيجة هذا المذهب الفوضوي الذي خلع كل القيود الاجتماعية والخلقية.

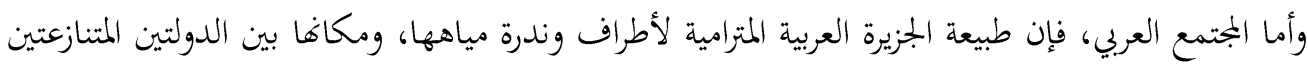
من حين لآخر فارس والروم، وطبيعة القبائل المتنقلة في الصحراء بكثنا عن مصادر المياه مع مواشيهم التي هي مصدر رزقهم وعيشهم؛ لذا كان التفرق والتشتت في الصحراء الواسعة سمة فارقة في المجتمع العربي، وكان الفقر يسود الأكثرين، والأخلاق متباينة(22). لقد كان الوضع الأمني لشبه الجزيرة العربية مرتبطا بالوضع السياسي والاجتماعي ارتباطا وثيقا، إذ كانت

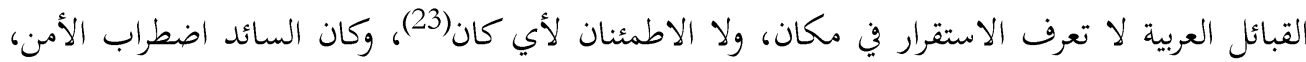
وكثرة السلب والنهب، وانتهاك الأعراض بين القبائل، ولكن لا يعني هذا على الإطلاق، بل كان في كل قبيلة مجلسا يتولى حماية القبيلة وتوفير الأمن الداخلي والخارجي لأبنائها(24). وحتى تتضح الفكرة فإنني سأقوم بالحديث عن أثر العمل التطوعي في تحقيق الأمن والاستقرار في المجتمع،

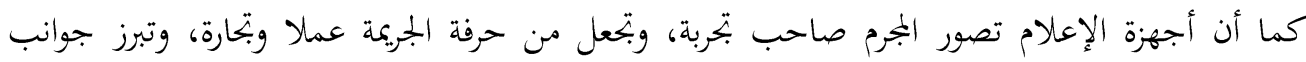

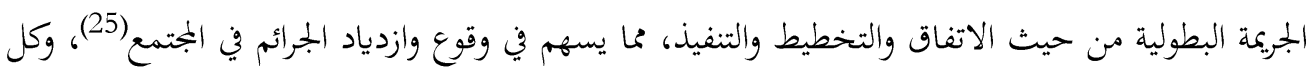

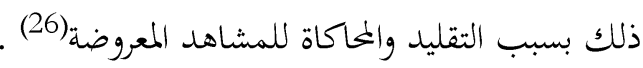

\section{المطلب الثالث: علاج مشكلة التسول:}

\section{أولاً: السنة النبوية}

إن من يطلع على السنة النبوية سيجد علاجاً شافياً وشاملاً لمشكلة التسول؛ فقد كان النبي يستعمل منهجا تربويا توجيهيا في معالجة هذه الظاهرة.

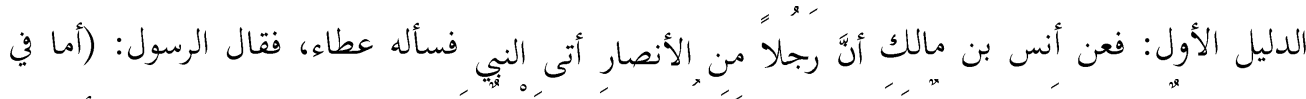

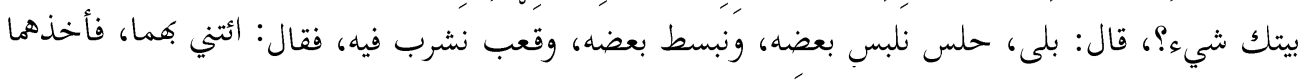

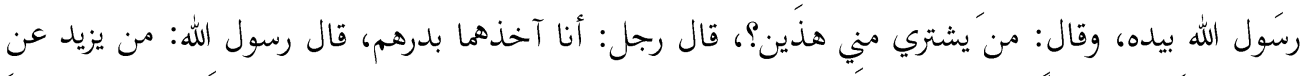

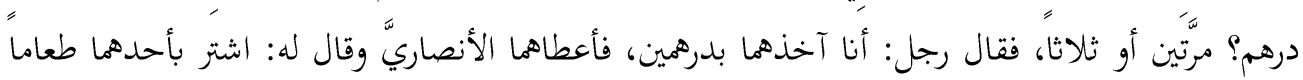

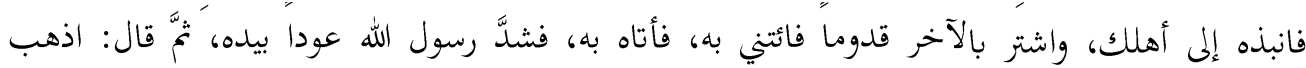


فاحتطب وبع، ولا أرينَّك خمسة عشر يوما، فجاء وقد أصاب عشرة دراهم، فاشترى ببعضها طعاماً

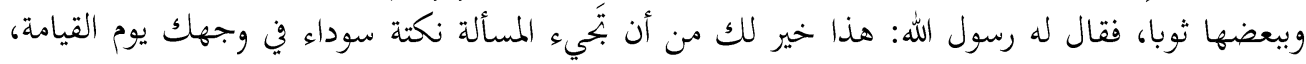

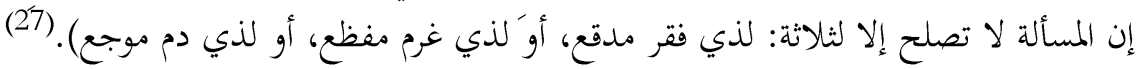

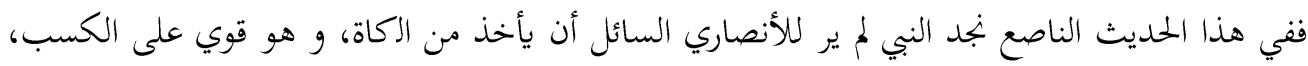
ولا يجوز له ذلك إلا إذا ضاقت أمامه المسالك، وأعيته الحيل، وعلى ولي الأمر أن يعينه في إتاحة الفرصة للكسب الحلال، وفتح باب العمل أمامه، كما أن النبي لم يعالج مشكلة السائل المختاج بالمعونة المادية

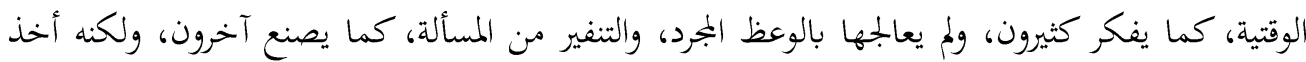

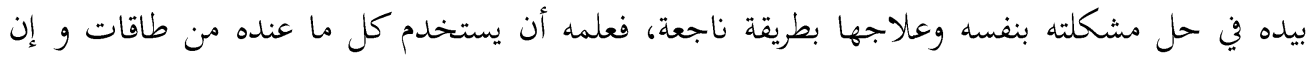
صغرت، وأن يستفيد ما يملك من الحيل و إن ضؤلت، فلا يلجأ إلى السؤال، وعنده شيء يستطيع أن ينتفع

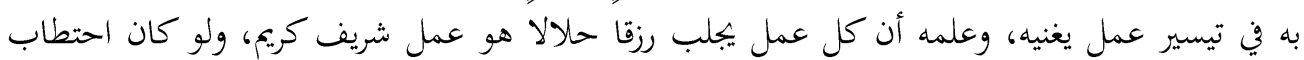

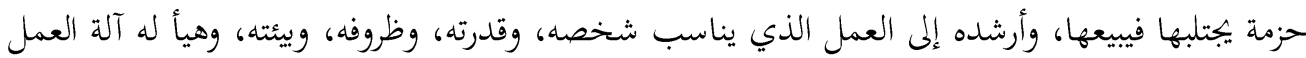
الذي أرشده إليه، ولم يدعه تائها. وبعد هذا الحل العملي لمشكلته لقنه ذلك الدرس النظري الموجز البليغ، في الزجر عن المسألة والترهيب

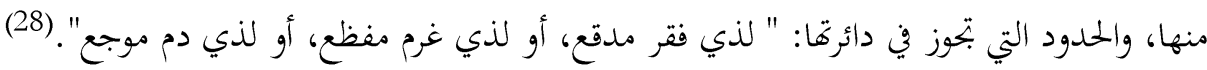

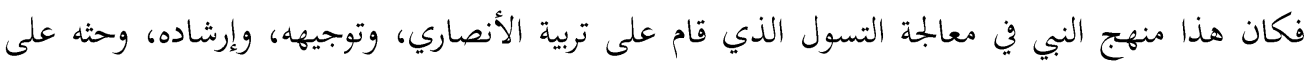
العمل، والأكل من كسب يديه، وحبذا لو اتبعنا نحن هذا المنهج النبوي القويم، وقبل أن نبدأ في محاربة

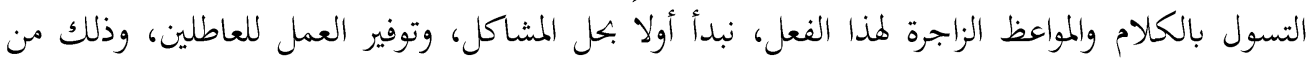
خلال التكافل والتعاون الاجتماعي. الدليل الثاني: الترهيب النبوي للتسول وطلب الأموال من الناس، وبين النبي صلى الله عليه وسلم عقوبة

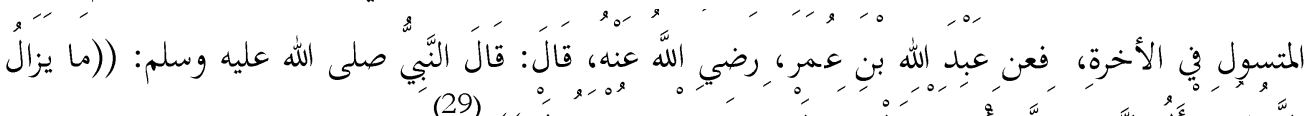

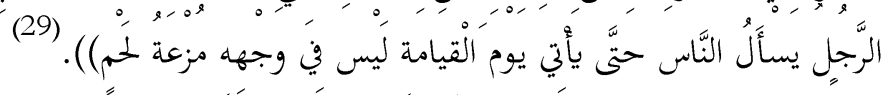

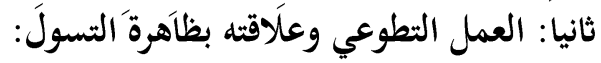

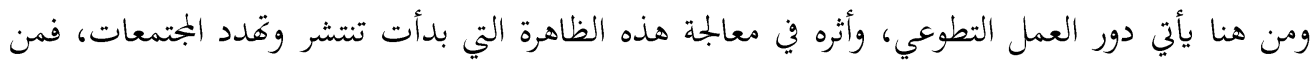

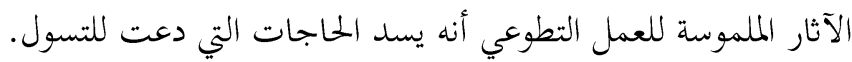
وهنا يأتي دور وأثر العمل التطوعي في الوقوف على مواطن الضعف، ومكامن النقص وعلاجها، من خلال

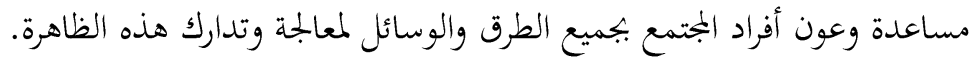


يعلُّ الفساد السبب الأول في تَنْفف الشعوب ودمار الدّول والحضارات وزوالها؛ فهو يؤدي إلى فقدان الدولة لعناصر التوازن، مما يؤدي إلى سهولة السيطرة عليها، وبالتالي اهيارها. تعددت أنواع الفساد التي تنتشر في فئرات وردي

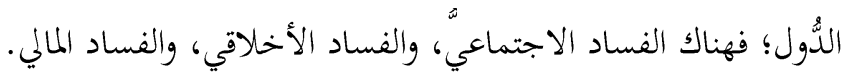
تنعكس آثار الفساد المالي والاقتصادي والسياسي والاجتماعي على البنية الاقتصادية والاجتماعية للبلد، فيتأثر مجهود التنمية وتحقيق العدالة الاجتماعية والتوزيع العادل للدخل الوطني، وتتجه الاستثمارات للقطاعات الهامشية، وتتوسع الفجوة بين الفقراء والأغنياء ويبرز التفاوت الطبقي، وتصبح ثروة البلاد في يد عدد قليل من المتنفذين، المستفيدين من هذا الواقع المريض. كما ينتج عن الفساد تكاليف مادية واجتماعية بعد أن تصبح هذه الجريمة نشاطا مربحا تتيح لفاعليها توسيع نشاطهم داخل دواليب الدولة، كما تكون

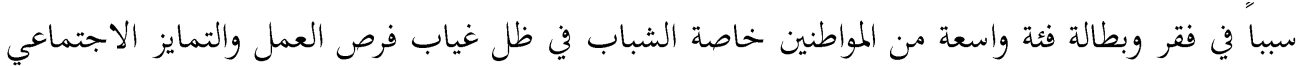
مما يؤدي إلى عزوفهم عن العمل الذي لا يوفر الدخل المالي الكبير، ويصير اهتمامهم في تحين فرص ممارسة الأنشطة الطفيلية والهامشية، وربما اللامشروعة كأعمال الغش والأنشطة التجارية المخظورة (30).

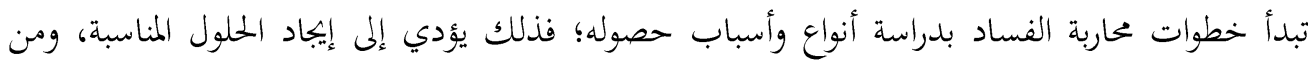
الطرق المقترحة لمحاربة التسول: 1- ترسيخ عقول تحافظ على نشوة الإسلام، وسلامة المجتمع من الانحراف الفكري الخطير في تدمير عقول الرجال.

2- تربية النفس على احترام الشرع؛ من خلال إيقاظ الضمير الذي يعلُّ شرطياً داخل كل شخص، وتنمية روح الانتماء للوطن وحبه وتقديم مصلحته على المصلحة العامة. 3- توخي الحيطة والحذر من الأشخاص المتسولين بالذات؛ فيجب مراقبة هكذا نماذج التي تمدد أمن البلد والاستخفاف بقدراته وامكانياته 4- وضع القوانين والأنظمة الصّارمة التي تُحارب الفساد وتلاحق الفاسدين؛ للقضاء عليهم، وتطهير الدّولة

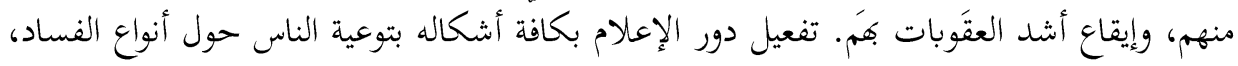
وطرق التعاون معا للقضاء عليه. الخاتمة تمثلت نتائج الدراسة فيما يلي: 1- الفقر، واليتم، والبطالة، وانحلال الأطر العائلية داخل المدينة، كلها عوامل تشجع على التسول. 
2- كشفت الدراسة عن عدة جوانب من حياة الفئات العمرية الطبقة المتردية بالمدينة والقرى ونتائج التهجير والتغريب، والاستئصال، تحت تأثير الفقر الذي صعدته أزمة السنوات الماضية. 3- تهديد المجتمع بالانحراف والسلوك الذي يعكس على أمن البلد.

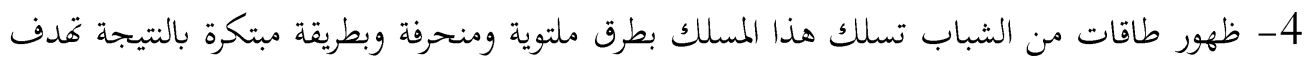
المى التسول.

5- ضياع طاقات كبيرة بسبب اعتمادهم على هذه ظاهرة مما يؤدي الشخص الى تحايل والكذب والخداع بطريقة بجذب المقابل بالدموع والتوسل والعطف والخطاب بروح ديني.

\section{التوصيات:}

1- قيام المؤسسات الدينية بما يخص الأوقاف والشؤون الإسلامية من عمل ورش وندوات وجلسات

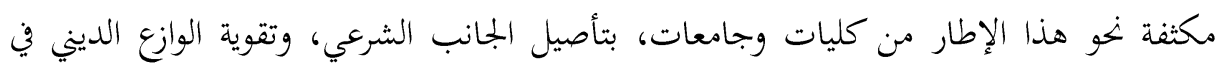
نغوس المتعلمين.

2- غرس مبادئ المواطنة في نفوس الناشئة، من خلال إعادة تقويم المناهج الدراسية بما يتلاءم

$$
\text { ومستجدات الواقع. }
$$

3- منع المسالك المؤدية إلى جرائم الاحتيال أو تضييعها، من خلال تفعيل الدور الأسري، باعتبارها

$$
\text { المخضن الأول للتنشئة الاجتماعية. }
$$

4- الحد من العقاب وسيلة للتهذيب الخلقي والنفسي والاجتماعي في المؤسسات العقابية.

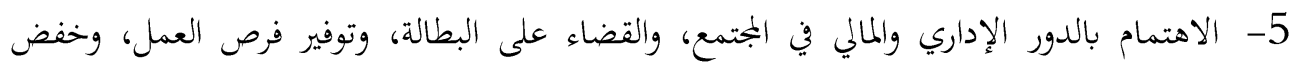
معدلات الفقر في المجتمع.

6- عدم التجاوب مع الأيدي الممدودة وعدم إعطاء المتسولين المال، وحثهم وتشجيعهم على العمل

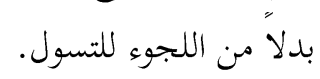
7- - دور رعاية، والتوعية بمخاطر التسول وعقوبته، وأثره السلبي على المجتمع. 8- توعية الأهل على تشجيع ابنائهم لتجنب هذه الظاهرة.

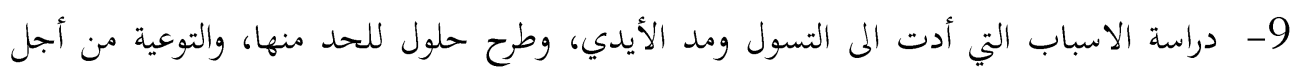
القضاء عليها واجتثاثها. 10-تقديم دعم والمساعدات المالية والعينية والاوراق النقدية؛ لكي يتم كفاية العتاجين وابعادهم عن التسول. 


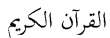

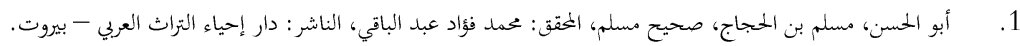

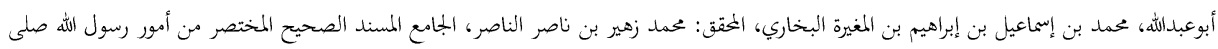

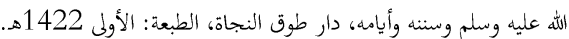

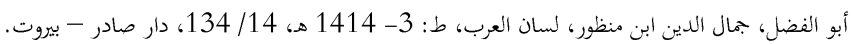

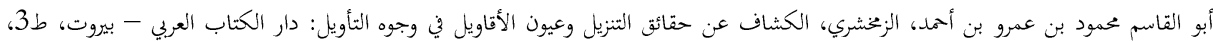

أبو جعفر، محمد بن جرير، الطبري، جامع البيان في تأويل القرآن: تحقيق: أحمد محمد شاكر، مؤسسة الرسالة.

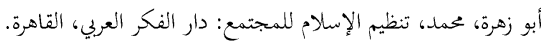

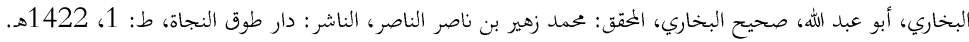

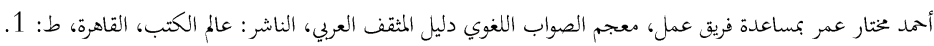

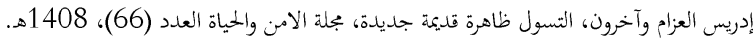

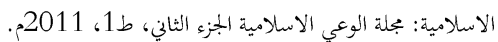
.6

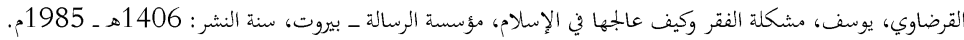

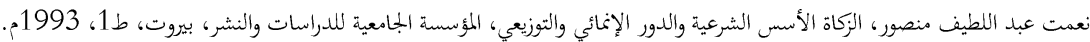

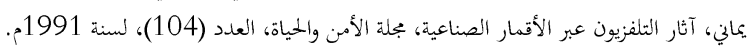

الاستجداء مأخوذة من الجدا والجدوى وهي العطية، جدا عليه يجدوا جداً. وأجدى فلان: أي أعطى، وأجداه أي أعطاه الجذوىى، وأجدى أيضاً بعمنى أصاب

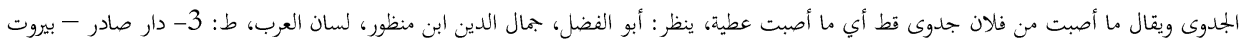

.13/14 1414

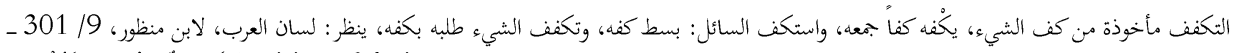

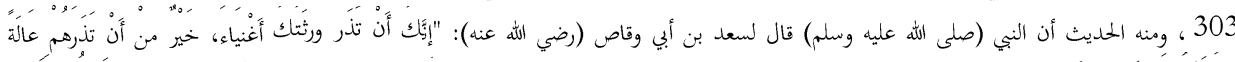

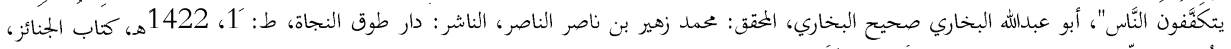

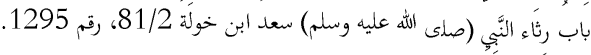




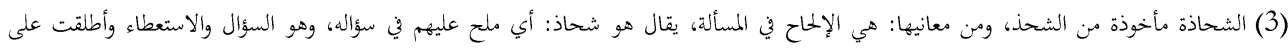

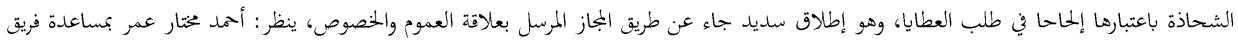

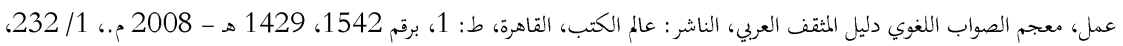
(4) ابن منظور، لسان العرب، 5 (5) 3902.

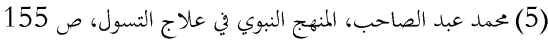

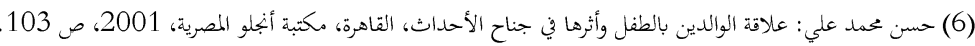

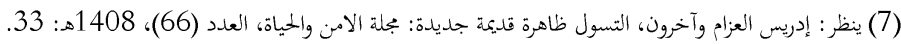

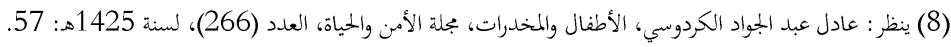

(9) ينظر : إدريس العزام وآخرون، التسول ظاهرة قديمة جديدة التيدة،

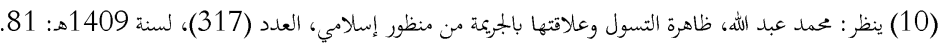

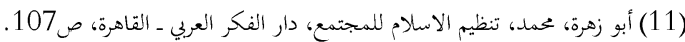

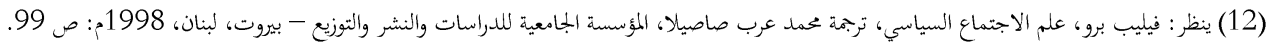

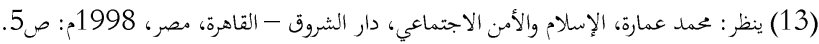

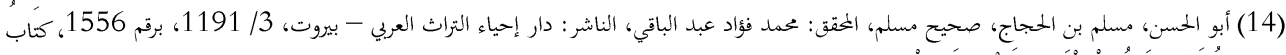

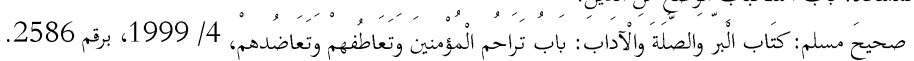

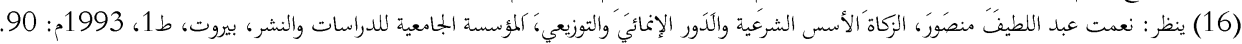

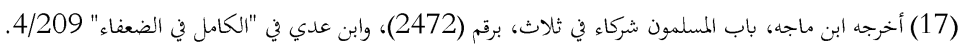

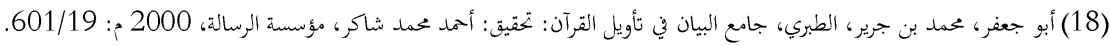

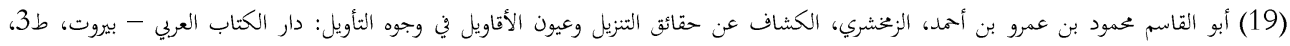
1407هـ: $469 / 3$

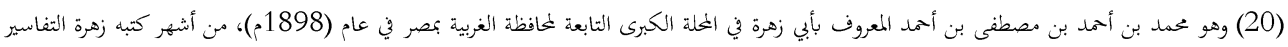

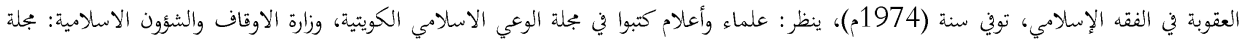
الوعي الاسلامية الجزء الثاني، ط1، الإي، توف سنة 2011م: 595.

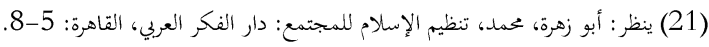

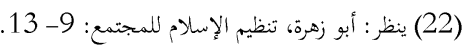

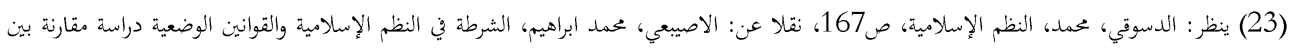

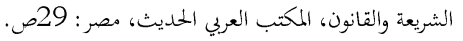

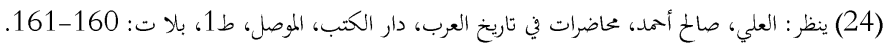

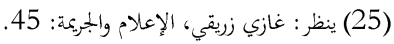

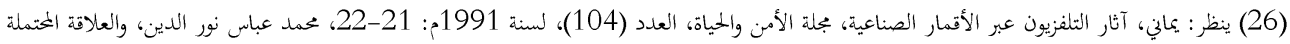

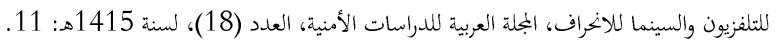
(28) سبق تخريجه: ص8

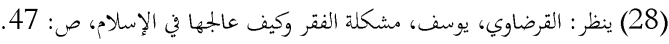

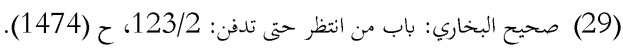

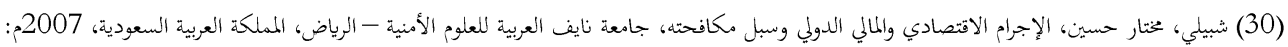

